\title{
PERCEPÇÃO DA PAISAGEM POR ESTUDANTES DE ESCOLAS DE IRATI - PR
}

\author{
PERCEPTION OF LANDSCAPE OF SCHOOL STUDENTS IN IRATI - PR
}

\author{
Mariângela Ceschim lurk¹, Daniela Biondi², Fernando Luís Dlugosz ${ }^{3}$
}

\begin{abstract}
RESUMO
Envolvendo estudantes de duas escolas estaduais do município de Irati, realizou-se uma pesquisa com o objetivo de verificar a percepção sobre a paisagem e os elementos que compõe quatro ambientes do município, relacionando com a sua concepção de meio ambiente. Para isso, foram utilizados substitutos de paisagem (fotografias) de pontos turísticos conhecidos da área urbana e rural, quantificado os elementos componentes das mesmas através de análise visual, além de questionários, onde realizou-se pré e pós-testes. Os dados foram analisados através do teste não-paramétrico Wilcoxon, teste do Quiquadrado e comparação do porcentual obtido. Os resultados do teste Wilcoxon comprovaram que, com relação ao total das séries analisadas, a diferença entre o pré e pós-testes para 34,61\% das perguntas realizadas foi altamente significativa ou significativa. Na realização do teste de Qui-quadrado para a verificação se houve diferença de resultados entre as escolas, obteve-se como resultado o valor de $\mathrm{P}=0,344$, onde os desvios não são significativos. Conclui-se, portanto, que a escola é um bom espaço para o aluno apropriar-se de conteúdos sobre a paisagem e contextualizá-los dentro de uma visão ambiental, entrelaçando com a sua vivência, modificando assim a realidade presente e futura.
\end{abstract}

Palavras-chave: Educação ambiental; Fotografias; Análise da paisagem.

\begin{abstract}
Involving students from two public schools in the municipality of Irati, it was carried out a research in order to verify the perception of landscape and the elements that compose four environments of the municipality, relating to its conception of environment. For this, landscape substitutes were used (photographs) of known tourist spots of the urban and rural areas, quantified the elements of the them through visual analysis, and questionnaires, which took place before and after the tests. Data were analyzed using the non-parametric Wilcoxon test, chi-square test and comparison of the percentage. The results of the Wilcoxon test showed that, relative to the total of the analyzed series, the difference between the pre- and post-tests for $34.61 \%$ of the questions asked was highly significant or significant. Regarding the chi-square test to check whether there was difference in results between schools, it was obtained as a result the value of $\mathrm{P}=0.344$, which the deviations are not significant. It follows, therefore, that the school is a good space for the student to appropriate content on the landscape and contextualize them within an environmental vision, intertwining with his experience, thus changing the present and future reality.
\end{abstract}

Keywords: Environmental education; Photography; Landscape analysis.

\footnotetext{
Recebido em 09.12.2016 e aceito em 24.03.2017

1 Bióloga. Doutoranda em Engenharia Florestal na Universidade Federal do Paraná. Curitiba/PR - Email: mciurk@yahoo.com.br

2 Engenheira Florestal. Doutora. Professora Titular da Universidade Federal do Paraná. Curitiba/PR. E-mail: dbiondi@ufpr.br

3 Engenheiro Florestal. Doutor. Professor Adjunto da Universidade Estadual do Centro-Oeste. Irati/PR. E-mail: f.dlugosz@gmail.com
} 


\section{INTRODUÇÃO}

Percepção é uma palavra de origem latina - perceptione - que pode ser entendida como tomada de consciência de forma nítida a respeito de qualquer objeto ou circunstância. $A$ circunstância em questão diz respeito a fenômenos experimentados e vivenciados. (MUCELIN; BELLINI, 2008; OLIVEIRA, 2012).

Os estudos a partir da abordagem perceptiva buscam conhecer a maneira pelo qual os seres humanos respondem ao seu ambiente físico, ou seja, a percepção que dele têm e o valor que nele depositam. A principal diferença entre o processo mental humano e animal é que as pessoas tem capacidade altamente desenvolvida para o comportamento simbólico (COSTA; COLESANTI, 2011).

Assim, a percepção é uma espécie de leitura de mundo que ocorre sob a influência de inúmeros fatores que determinam a atitude do indivíduo em relação ao ambiente percebido. Em se tratando das questões ambientais contemporâneas, as diferentes condutas e formas de relacionamento humano com o seu ambiente refletem essas diferentes vertentes da percepção (OLIVEIRA; VARGAS, 2009).

Isso pode ser observado quando analisa-se a qualidade das paisagens. Estudos de percepção constituem uma visão ímpar, uma vez que, a investigação e compreensão dos sentimentos e valores têm uma papel importante para a formação de juízos de valor e atitudes que orientam ações sobre os espaços (COSTA; COLESANTI, 2011).

O meio ambiente é percebido pelos indivíduos de forma múltipla e diferenciada, uma vez que a compreensão se dá sob uma perspectiva subjetiva apoiada numa realidade concreta (GEERDINK; NEIMAN, 2010).

O estudo da percepção ambiental é de fundamental importância. Onde pode-se descrever os múltiplos modos de vida reveladores do real sentido de inserção do ser humano no seu ambiente. É somente na redescoberta desses modos de viver e de se relacionar com a natureza, o lugar habitado e a coletividade que se pode ancorar uma postura sensível e dessa maneira, podem ser destinadas ações concretas de educação ambiental (MARIN, 2008; ARAUJO et al., 2010; LACERDA et al., 2010).

Segundo as diretrizes curriculares orientadoras para educação básica do Estado do Paraná, o professor da disciplina de Ciências é o responsável pela mediação entre o conhecimento científico escolar e deve lançar mão de encaminhamentos metodológicos que utilizem recursos diversos, planejados com antecedência, para assegurar a interatividade no processo ensino-aprendizagem e a construção de conceitos de forma significativa pelos estudantes (PARANÁ, 2008a).

O conteúdo de análise da paisagem vem ao encontro com esses interesses e pode ser 
selecionado para a abordagem em sala de aula, a partir do cotidiano escolar, e do próprio questionamento dos estudantes, remetendo-se a uma metodologia de problematização, baseada nos princípios filosóficos de Freire, o qual explicita que quando o homem compreende sua realidade, pode levantar hipóteses sobre o desafio desta realidade e procurar soluções (FREIRE, 1979).

Em vista disso, o objetivo geral do trabalho foi verificar a percepção de estudantes de duas escolas estaduais, sobre a paisagem e os elementos que compõem quatro ambientes do município de Irati, relacionando com a sua concepção de meio ambiente, a fim de definir estratégias de educação ambiental.

\section{MATERIAL E MÉTODOS}

\section{Área de estudo}

O município de Irati está localizado na zona fisiográfica de Irati, uma das onze em que o Paraná se divide. Encontra-se na sub-região dos pinhais, no segundo planalto do Paraná ou planalto de Ponta Grossa, localizando-se entre as coordenadas geográficas: $-25^{\circ} 25^{\prime} 05^{\prime \prime}$ a $25^{\circ} 32^{\prime} 38^{\prime \prime}$ de latitude Sul e -50³2'42" a -5042'05" de longitude Oeste.

Situa-se à distância de $138 \mathrm{~km}$ em linha reta na direção $88^{\circ} 21^{\prime}$ ' Oeste e a 150,34km pela BR 277, de Curitiba, capital do Estado, fazendo divisa com os municípios de Imbituva, Prudentópolis, Inácio Martins, Rio Azul, Rebouças e Fernandes Pinheiro (Figura 1).

Situa-se na região centro-sul do estado, onde município tem altitude média de 812 metros. O clima da região, baseando-se na classificação de Köppen, é do tipo Cfb: subtropical úmido mesotérmico caracterizado por verões frescos, geadas severas e frequentes e sem estação seca. A altitude é de $885 \mathrm{~m}$ e a vegetação é caracterizada pela Floresta Ombrófila Mista Montana (FIGUEIREDO-FILHO et al., 2010).

A população do município de Irati foi estimada em cerca de 60.070 habitantes, em 2016, pelo IBGE, onde a maior parte da população encontra-se no perímetro urbano (IBGE, 2016).

Em um século de existência, as atividades econômicas que no início da colonização eram basicamente rurais, diversificaram-se e a área urbana desenvolveu-se. A pressão sobre o ambiente aumentou significativamente e o rio das Antas, que tem sua nascente e grande parte de seu curso localizados dentro da área urbana do município, apresentou sérios problemas relacionados à qualidade da água e à supressão da floresta ciliar (VENÂNCIO; OLIVEIRAFILHO; DISPERATI, 2010). 


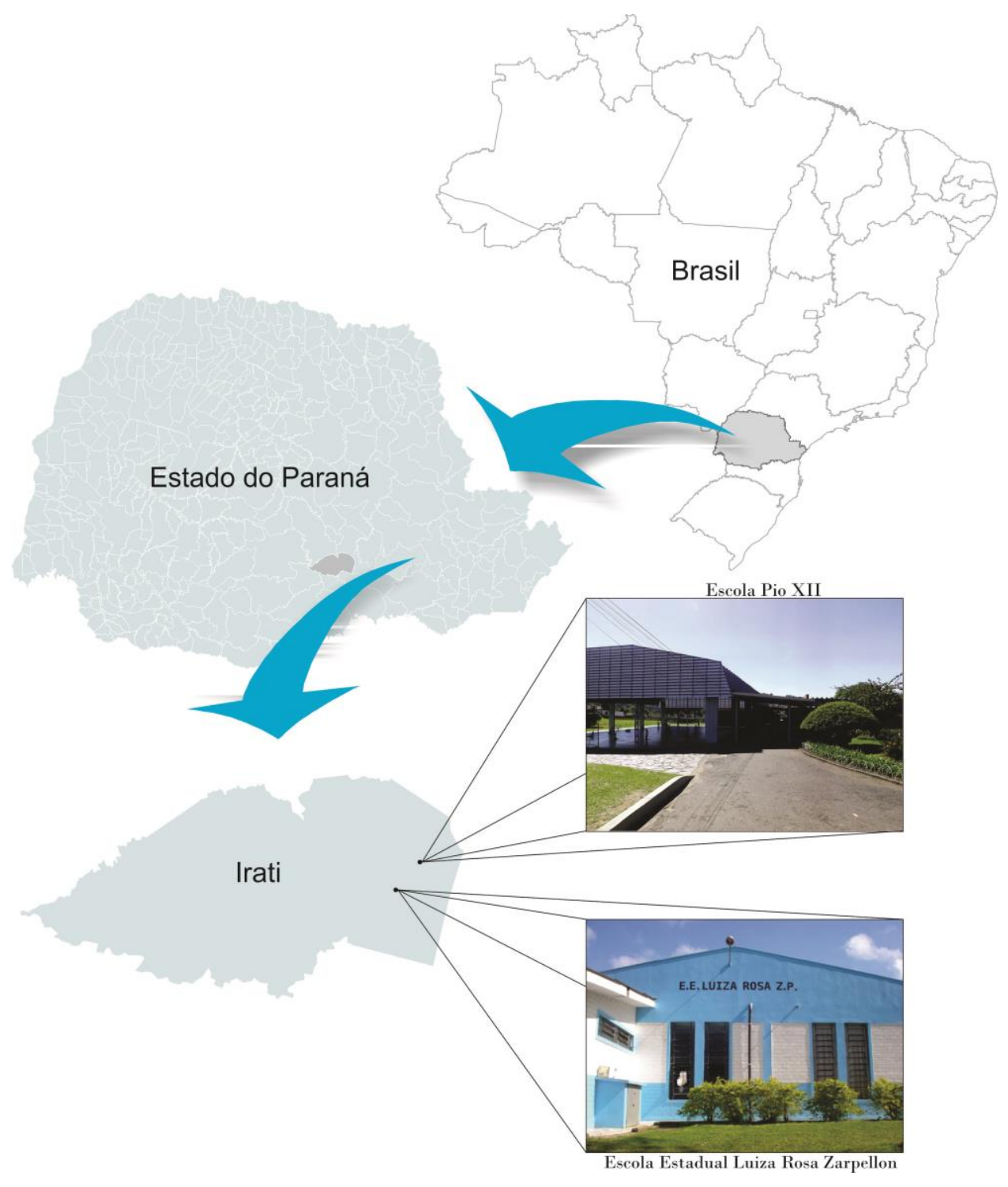

Figura 1. Localização da área de estudo

Figure 1. Location of the study area

\section{Escola Estadual Pio XII}

A Escola Estadual Pio XII fica situada na rua São Pedro Canísio, n 89, no bairro Canisianas, na área urbana do município de Irati.

Foi criada com o apoio do Governo do Estado do Paraná, através do Decreto ํo 5.565/86 de 01/01/87. Funciona juntamente com o Colégio São Pedro Canísio, pois o prédio pertence à Congregação das Irmãs Canisianas e parte dele é locado para o Estado.

Oferta o Ensino Fundamental aos estudantes pertencentes à classe de nível sócioeconômico baixo e médio. O estabelecimento teve desde o início a preocupação de criar condições para os estudantes participarem com responsabilidade no desenvolvimento da comunidade. 
Atualmente, conta com vinte e cinco professores(as), dez funcionárias, uma professora pedagoga, uma diretora, 19 turmas e 332 estudantes, divididos no período da manhã e tarde. A escola oferece apoio especializado para estudantes com maiores dificuldades nas Salas de Apoio de Matemática e Língua Portuguesa (estudantes de $6^{\circ}$ e $9^{\circ}$ anos), Sala de Recursos e Sala de Recursos Multifuncional.

\section{Escola Estadual Luiza Rosa Zarpellon Pinto}

A Escola Estadual Professora Luiza Rosa Zarpellon Pinto, situada na Rua Rio Ipiranga, s/n Bairro Lagoa, também na área urbana no município de Irati.

Foi criada e autorizada a funcionar com a Resolução no-448/91 DOE 27/02/91, para ministrar de forma gradativa no período diurno o ensino das quatro últimas séries do Ensino Fundamental, iniciando no ano de 1991.

No mesmo prédio em período contrário funciona a Escola Municipal da Lagoa, mantida pela Prefeitura Municipal de Irati, que atende a clientela de Primeiro ao Quinto ano do Ensino Fundamental.

O nome dado à escola foi em homenagem à Professora Luiza Rosa Zarpellon Pinto que representou um papel importante não só como professora dedicada que agia com espírito de solidariedade, principalmente com os estudantes mais carentes, mas porque transmitia esse mesmo carinho e amor para fora da sala de aula, envolvendo-se na área social.

Atualmente, conta com trinta e um professore(as), cinco funcionárias, uma professora pedagoga, uma diretora, 14 turmas e 299 estudantes.

Em atendimento aos estudantes que apresentam problemas na aprendizagem, a escola conta com Salas de Apoio de Matemática e Língua Portuguesa (estudantes de $6^{\circ}$ e $9^{\circ}$ anos), Sala de Recursos e Sala de Recursos Multifuncional.

\section{Seleção das imagens}

Foram selecionados quatro substitutos da paisagem (fotografias) de pontos turísticos conhecidos, que se localizam no município de Irati, tanto na área urbana quanto na área rural. Os locais selecionados foram: Colina Nossa Senhora das Graças, Parque Aquático de Irati, Cachoeira do Itapará e Cachoeira do Pinho de Baixo.

A colina Nossa Senhora das Graças, localiza-se numa via de fácil acesso no município, e pode ser visualizada de praticamente todos os pontos da cidade. A "Santa" (Figura 2), como é conhecida popularmente no município, é uma imagem de aproximadamente 22 metros de altura, a qual foi idealizada e construída para celebrar os 50 anos de Irati, no ano de 
1956. A imagem é esculpida em 70 peças, por Ottaviano Papaiz, da Oficina Artística de Escultor e Estucador de Campinas (SP) (FERNANDES; MENEZES, 2009).

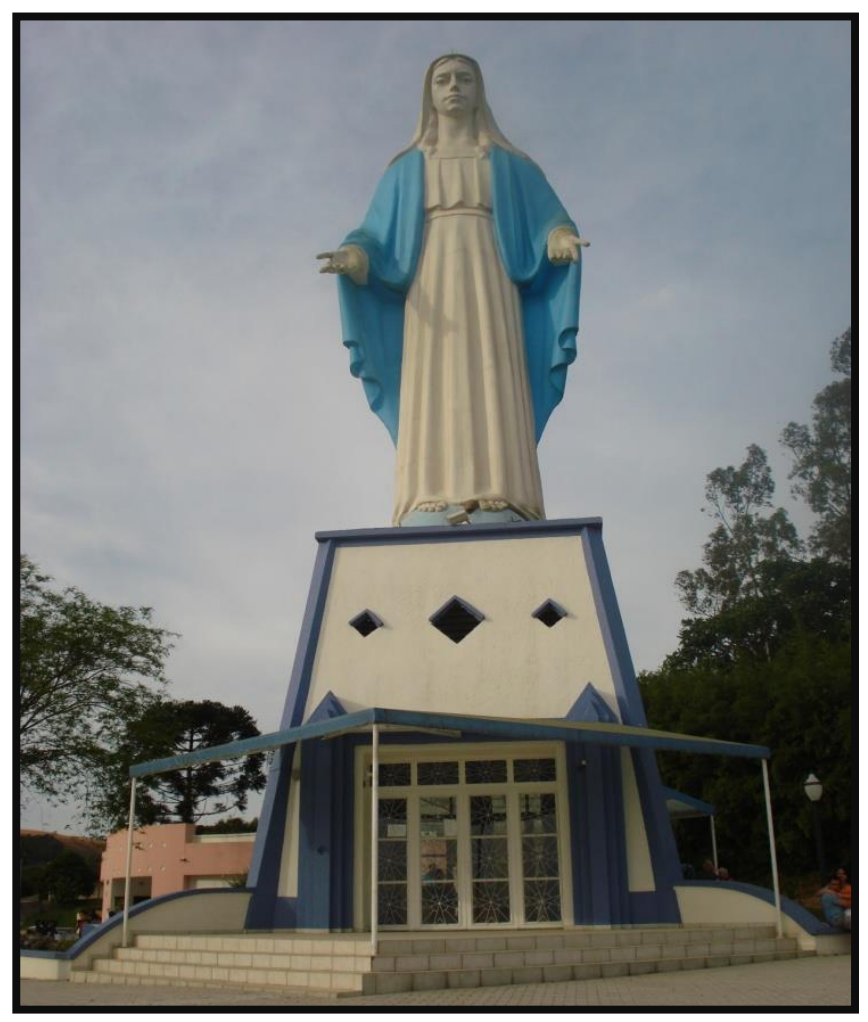

Figura 2. Imagem de Nossa Senhora das Graças de 22 metros de altura Figure 2. Image of Nossa Senhora das Graças with 22 meters high

O Parque Aquático e de Exposições Santa Terezinha possui $79.000 \mathrm{~m}^{2}$, e foi inaugurado em 1988 (Figura 3). É um espaço de lazer e recreação bastante frequentado, principalmente nos finais de semana. É uma das poucas áreas verdes e arborizadas, localizase na área urbana do município. Além do lago, fazem parte do parque o Pavilhão de Exposições João Wasilewski com 1.017,50 m² (que abriga importantes eventos municipais, como a Festa do Pêssego), mini-estação ferroviária com 79,88 $\mathrm{m}^{2}$, trenzinho que circunda o local em $870 \mathrm{~m}$ de trilhos, pedalinhos, pontes, diversos brinquedos espalhados por toda a área, churrasqueiras, prédio central com $108,28 \mathrm{~m}^{2}$, postos médico e odontológico e o Centro Cultural do Rio Bonito, onde ocorrem projetos, cursos e exposições. O complexo esportivo inclui ginásio, quadras poliesportivas de areia, quadras de tênis, pista de caminhada pavimentada com extensão de $1.050 \mathrm{~m}$. e academia de ginástica ao ar livre (FERNANDES; MENEZES, 2009). 


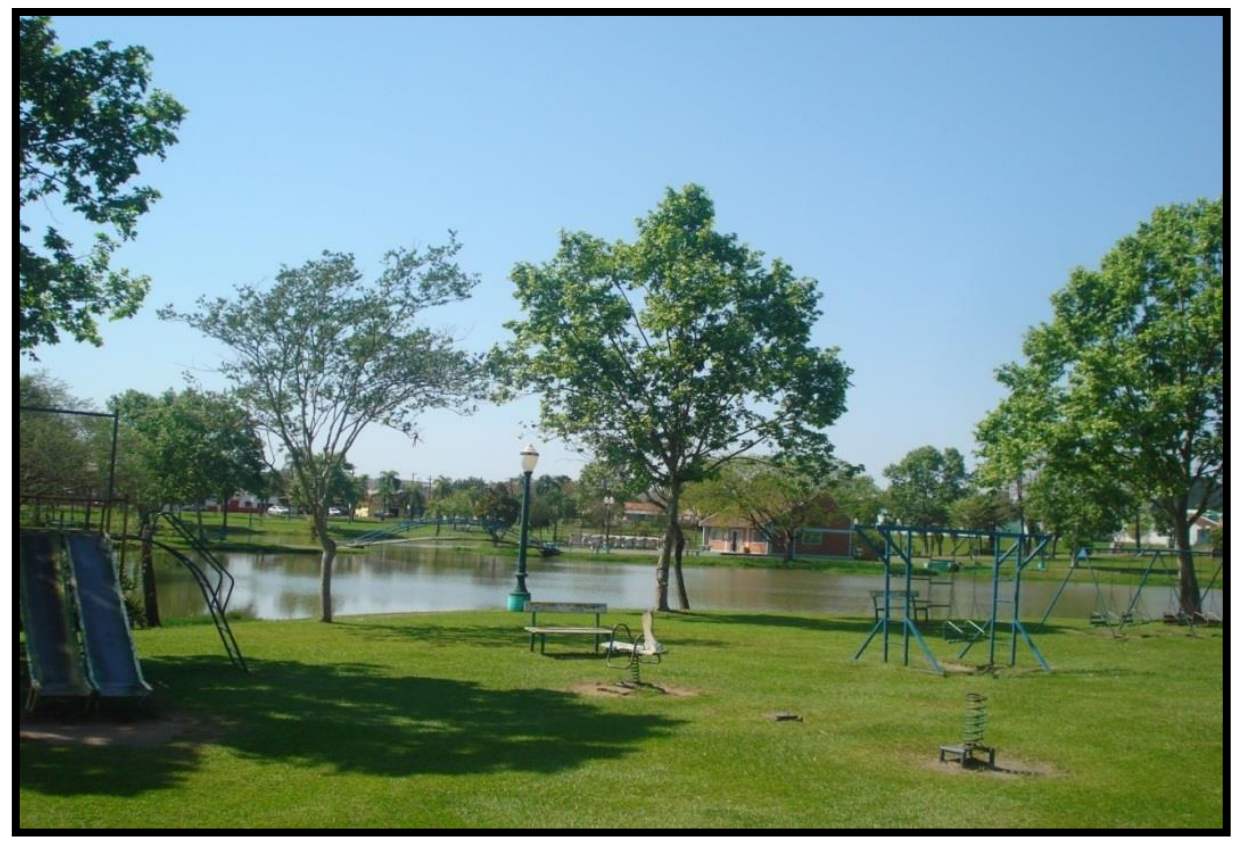

Figura 3. Parque Aquático de Irati Figure 3. Water Park of Irati

A região de Irati conta com inúmeras quedas d'água e cachoeiras espalhadas pelo município. A cachoeira da localidade do Itapará (Figura 4) fica distante aproximadamente 45 quilômetros da sede do município, numa propriedade particular, porém com livre acesso dos visitantes. É um local de lazer bastante frequentado pelos moradores da localidade, além de pessoas de Irati e de outras cidades. Não possui uma estrutura turística, porém configura-se como uma importante área de lazer no município.

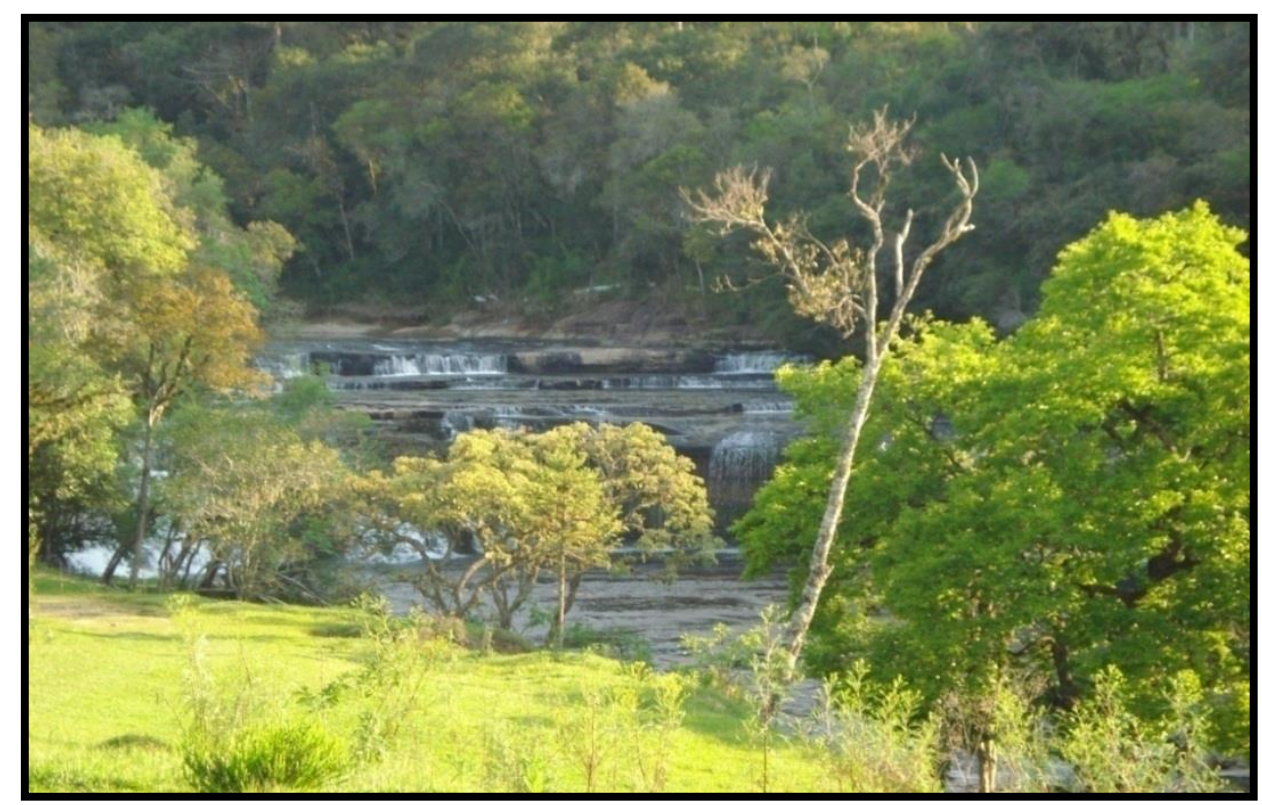

Figura 4. Cachoeira da localidade do Itapará

Figure 4. Waterfall of Itapara location 
A localidade do Pinho de Baixo, distante 25 quilômetros da sede do município, também numa propriedade particular, onde o acesso é restrito aos visitantes, mas ainda sim muito frequentada pelos moradores de Irati e região (Figura 5).

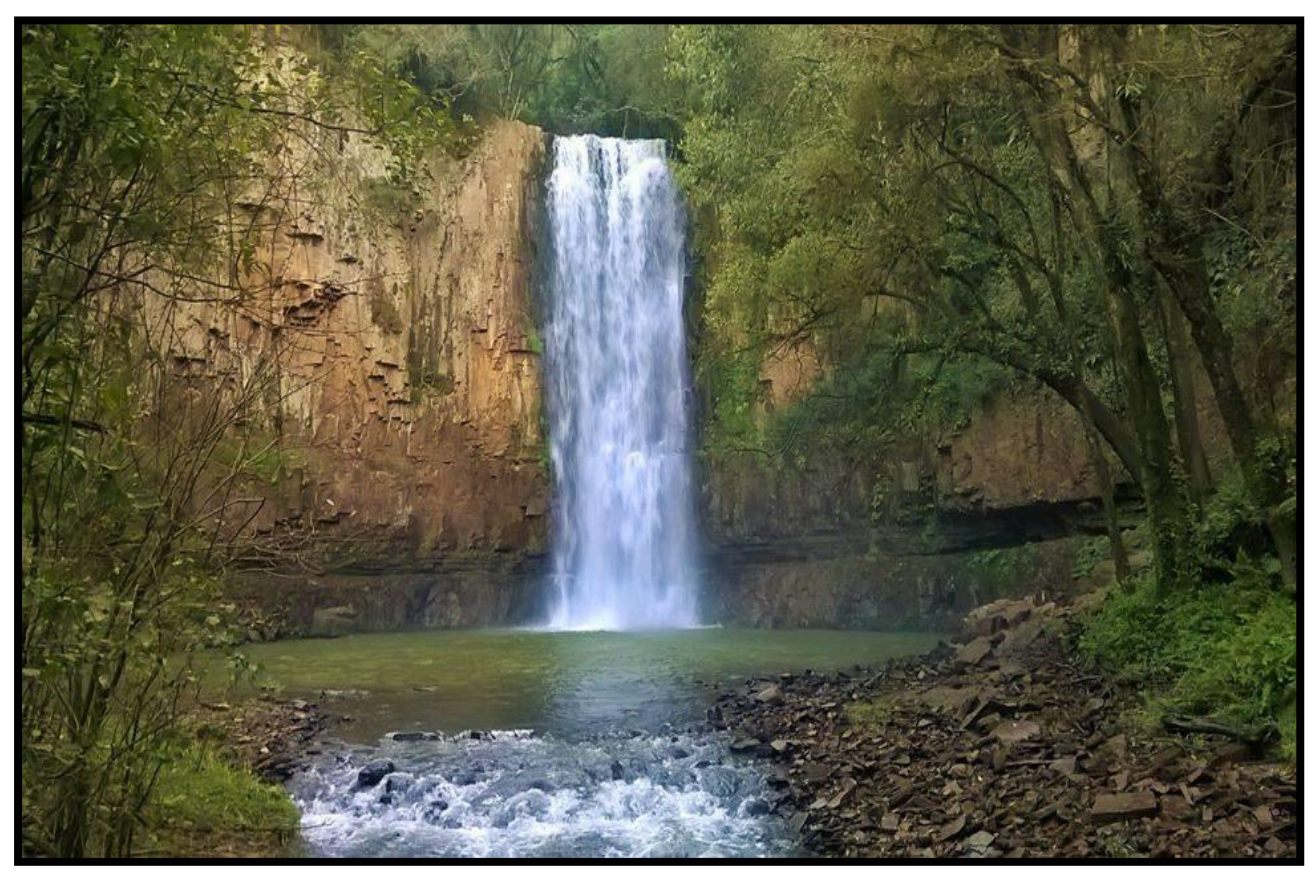

Figura 5. Cachoeira da localidade do Pinho de Baixo

Figure 5. Waterfall of Pinho de Baixo location

As fotos foram feitas entre os dias 03 e 07 de agosto de 2015, entre as oito e onze horas da manhã, em dias preferencialmente ensolarados.

\section{Análise visual dos componentes da paisagem}

Com o objetivo de analisar os elementos que compuseram cada paisagem selecionada, esta pesquisa utilizou como base a metodologia utilizada Silva e Biondi (2014) e Bobrowski, Vashchenko e Biondi (2010), onde foram realizadas algumas adaptações.

As quatro imagens dos pontos turísticos de Irati foram analisadas de acordo com os componentes paisagísticos neles existentes e em cada imagem digital foram realizados os seguintes procedimentos:

a) Divisão das quadrículas de $0,5 \times 0,5 \mathrm{~cm}$ e sobreposição do grid, totalizando 580 quadrículas (Figura 6);

b) Impressão das fotos e sobreposição de um acetato transparente;

c) Análise visual de cada quadrícula e atribuição de símbolos para cada componente da paisagem, com a atribuição de símbolos para as classes;

d) Tabulação do número de quadrículas preenchido para cada classe; 
e) Cálculo do percentual de cada classe para a imagem como um todo.

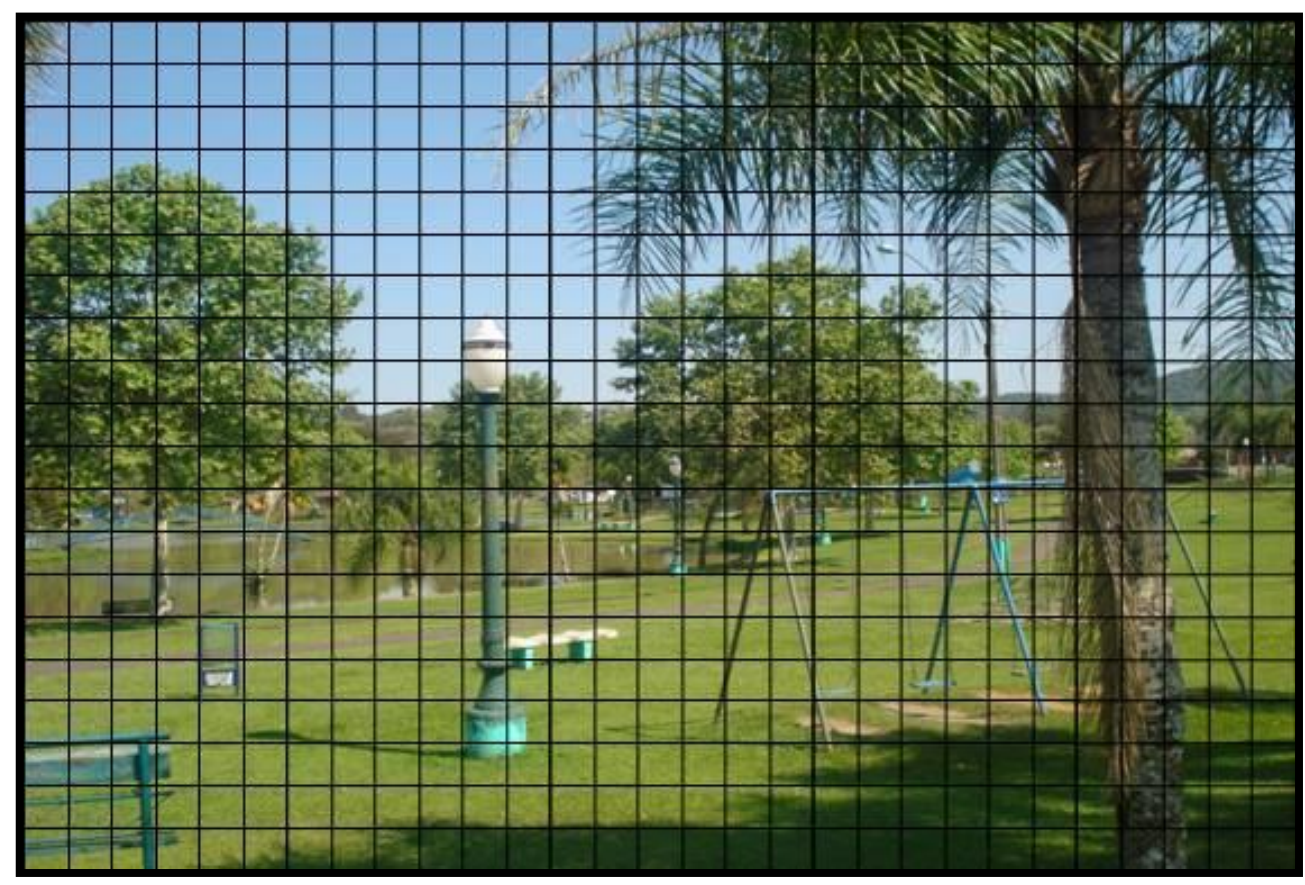

Figura 6. Fotografia com o grid de quadrículas (Adaptado de Silva e Biondi (2014)) Figure 6. Photograph with the squares grid (Adapted from Silva e Biondi (2014))

\section{Análise qualitativa e quantitativa dos dados}

A Lei n 17505/2013 do estado do Paraná, estabelece que a educação ambiental será desenvolvida como uma prática integrada, interdisciplinas, transdiciplinar e transversal no currículo escola, contínua e permanente em todos dos níveis e modalidades da educação formal (PARANÁ, 2013).

Para analisar qualitativa e quantitativamente as esse estudo, foi desenvolvido um questionário, que teve como objetivo principal avaliar, nos estudantes, os seguintes aspectos:

a) o entendimento das ocorrências antrópicas como modificadoras da paisagem;

b) o reconhecimento do conceito fundamental de paisagem;

c) a compreensão dos elementos estruturais componentes da paisagem;

d) a percepção da paisagem como um elemento de conservação e preservação de cenários naturais.

A avaliação desta pesquisa foi baseada em Camargo e Ferrari (2009) e Carrillo e Biondi (2007) e constitui-se de quatro etapas:

a) Pré-teste: questionário aplicado no primeiro contato, com questões subjetivas e objetivas, sobre todos os temas que seriam trabalhados. 
b) Teste: aplicado após a abordagem de um tema, com avaliações diversificadas (redações, cartas, desenhos, entre outros). A finalidade dos testes é reafirmar o conteúdo.

c) Pós-testes: questionários sobre os temas trabalhados, com algumas questões idênticas ao aplicado no último contato, sendo idêntico ao pré-teste.

\section{Coleta e análise dos dados}

Para a obtenção dos dados segundo o modelo de avaliação do PPP, as turmas escolhidas para a realização das atividades foram os sextos anos $A, B$ e $C$ do período vespertino da Escola Estadual Pio XII e os sextos anos A e B do período matutino da Escola Estadual Luiza Rosa Zarpellon Pinto, totalizando 130 estudantes, com idades entre 11 e 15 anos.

Inicialmente, foram distribuídos os questionários e solicitou-se que fossem respondidos, utilizando-se os conhecimentos que tinham sobre o assunto e os locais exibidos. Além dos conhecimentos sobre os conceitos de paisagem, os estudantes deveriam informar a idade e o bairro onde residiam.

Na Figura 7 pode-se observar o modelo de questionário aplicado nas escolas.

Nas aulas seguintes, os assuntos relativos à análise da paisagem foram expostos com o auxílio da TV multimídia e apresentações com o projetor multimídia e lousa digital.

As paisagens que não foram identificadas pelos estudantes foram impressas e distribuídas aos estudantes, os quais deveriam pesquisar com a família onde se localizavam.

Nas próximas aulas foi então realizado o pós-teste e as categorias adotadas para a correção das respostas foram: a) satisfatória: conteúdo coerente; b) aceitável: noção sobre o assunto; c) não aceitável: conteúdo incoerente; e d) não respondida. 


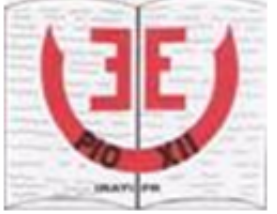

\section{Escola Estadual Pio XII. Ensino Fundamental \\ Ciências - Segundo Bimestre - Sexto Ano Professora Mariângela}

Nome:

Bairro onde mora:

Observe a paisagem exibida e responda:

1) Como você acredita que era esse ambiente antes da intervenção humana?

2) Que tipo de modificações os seres humanos realizaram nessa paisagem?

3) Que elementos naturais podemos identificar nessa paisagem? Ordene conforme aparece em maior número.
( ) vegetação
( ) temperatura
( ) rios
( ) nuvens
( ) montanhas
( ) animais

4) Que elementos culturais podemos identificar nessa paisagem? Ordene conforme aparece em maior número.
( ) estrada
( ) plantação
( ) casas
( ) prédios
( ) indústrias

( ) redes de água

( ) redes de esgoto

( ) redes elétricas

5) Quantos planos podemos identificar na paisagem?
( ) somente um
( ) dois planos
( ) três planos

6) A cor predominante é da paisagem é:
( ) verde
( ) azul
( ) amarela
( ) marrom

7) Quais forças naturais transformam a paisagem? Marque quantas achar necessário
( ) água
( ) ventos
( ) terremotos
( ) vulcão
( ) animais
( ) plantas
( ) geadas

8) Como os seres humanos transformam a paisagem?

9) Você acredita que pode existir um lugar no planeta onde o ser humano jamais esteve?

Observe essas outras paisagens e responda as seguintes questões:

1) Você conhece ou já visitou algum desses locais?

( ) sim, sempre ( ) sim, algumas vezes ( ) sim, conheço ( ) não

2) Onde se localizam?
( ) Outro país. Qual?
( ) Outra cidade. Qual?
( ) Irati

3) Qual é o nome desses locais?

\begin{tabular}{|c|c|c|c|}
\hline & & & \\
\hline 1 & 2 & 3 & 4 \\
\hline
\end{tabular}

4) Quais elementos você consegue identificar nessa paisagem?

\begin{tabular}{|c|c|c|c|}
\hline & & & \\
\hline 1 & 2 & 3 & 4 \\
\hline
\end{tabular}

5) Qual paisagem você visitaria?

$\begin{array}{lll}1 & \square \square \\ 2 & \square\end{array}$

6) Por que?

\begin{tabular}{|c|c|c|c|}
\hline & & & \\
\hline 1 & 2 & 3 & 4 \\
\hline
\end{tabular}

7) Qual paisagem você não sente vontade de visitar?

$\square 1 \square 2 \square 3 \square 4$

8) Por que?

\begin{tabular}{|c|c|c|c|}
\hline & & & \\
\hline 1 & 2 & 3 & 4 \\
\hline
\end{tabular}

Figura 7. Modelo de questionário aplicado nas escolas

Figure 7. Questionnaire model applied in schools 
As informações foram então tabuladas e armazenadas em planilha Excel, e então analisadas:

1 - Através do teste não-paramétrico Wilcoxon matched-pair signed-ranks test (SIDNEY, 1975), que teve como objetivo medir se houve diferenças significativas entre pré e pós-testes, para cada uma das respostas. Este teste é indicado quando o estudo abrande duas amostras dependentes as quais proporcionam scores de diferenças que podem ser ordenados seus valores, onde, quando a diferença for maior ou igual que 0,01 será classificado como altamente significativa, se estiver entre 0,01 e 0,05, será tratada como significativa e se o nível de diferença for maior que 0,05 será interpretado como não significativo, conforme observado em Carrillo e Biondi (2007) e Biondi e Falkowski (2009).

2 - Utilizando-se o teste do Qui-quadrado que comparou o resultado obtido entre os Colégios, como observado em Fandi e Melo (2001).

3 - Por meio da comparação do porcentual obtido entre o pré e o pós-teste, verificando se houve incremento ou não na pontuação obtida pelo estudante.

\section{RESULTADOS E DISCUSSÃO}

\section{Análise das imagens}

A coleta de dados foi realizada em duas escolas estaduais da área urbana do município de Irati, nos meses de agosto e setembro de 2015, no período matutino e vespertino, totalizando 130 estudantes, nascidos entre os anos de 2000 a 2004 (Figura 8).

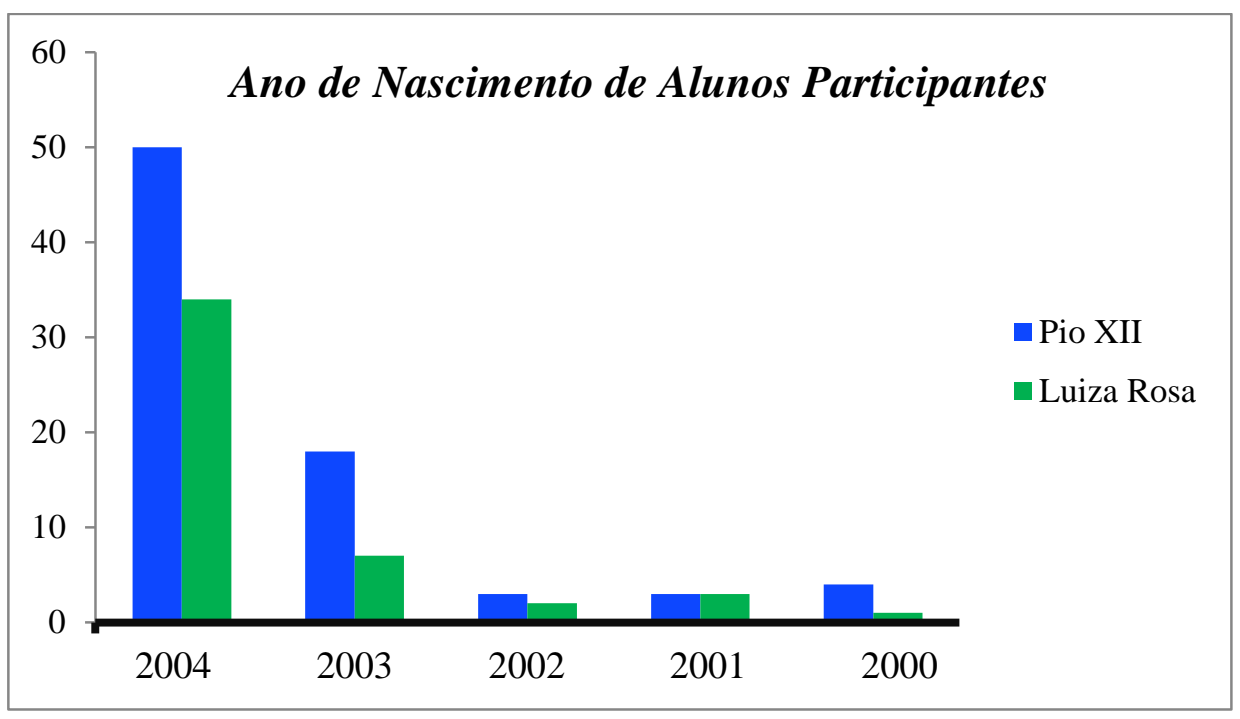

Figura 8. Ano de nascimento dos estudantes participantes

Figure 8. Year of birth of participating students 
Os participantes da pesquisa residem em 12 bairros do município, todos localizados exclusivamente na área urbana, conforme pode ser observado na Figura 9.

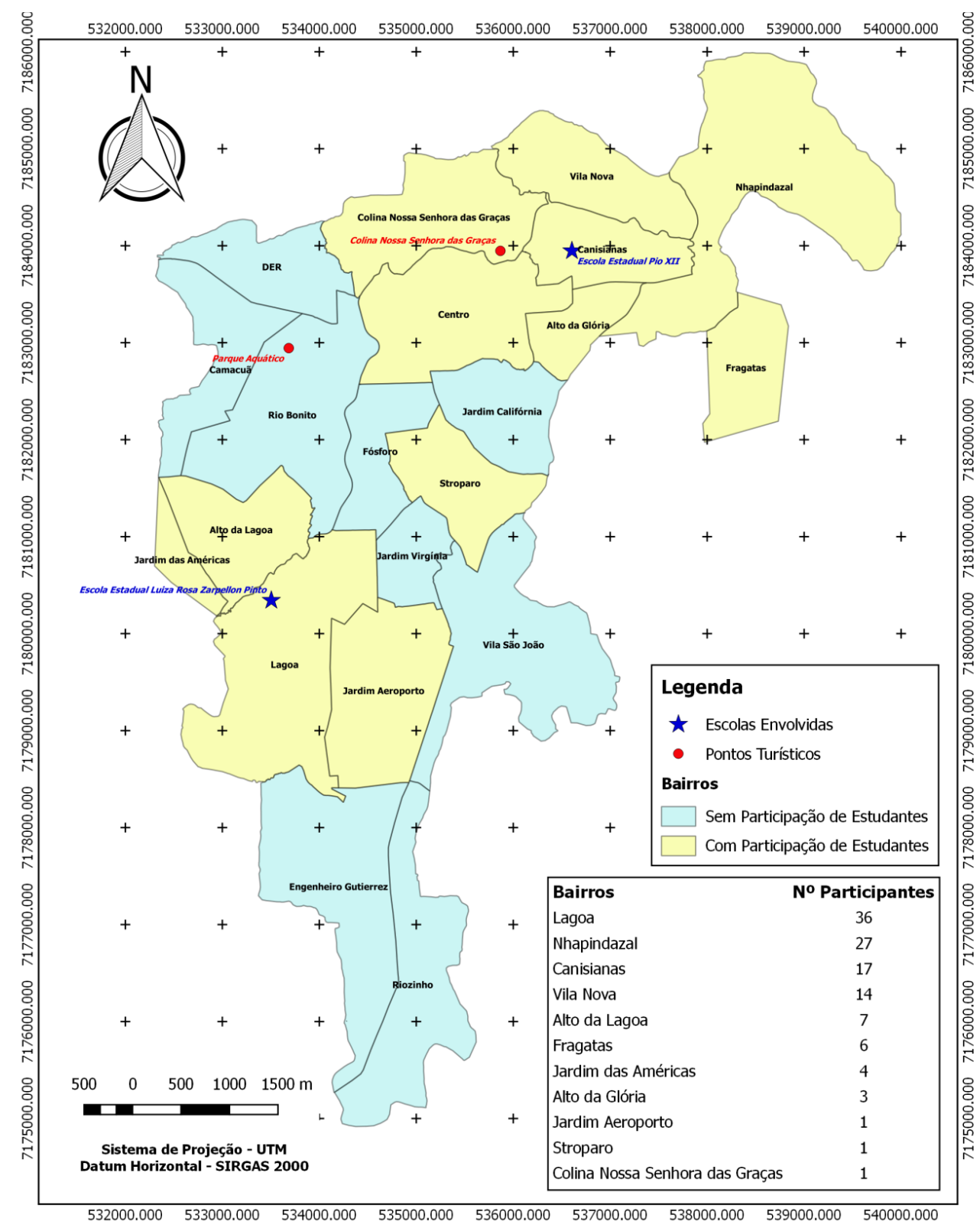

Figura 9. Localização dos bairros de residência dos envolvidos na pesquisa e a localização de dois pontos turísticos urbanos

Figure 9. Location of the residence neighborhoods of those involved in research and the location of two urban tourist spots

$\mathrm{Na}$ imagem que se referia à primeira parte do questionário, onde eram discutidos sobre o ambiente antes e depois da intervenção humana, elementos identificados na paisagem (naturais e culturais), número de planos e cor predominante, foram identificados nove 
componentes da paisagem, onde a grama teve maior porcentagem de ocupação na foto (225 quadrículas), com $38,79 \%$, ficando evidente a cor predominante da paisagem como sendo a verde, identificada pelos estudantes em $100 \%$ dos questionários.

Os substitutos de paisagem seguintes, os quais se referiam à segunda parte do questionário, foram igualmente analisados, e o resultado das classes identificadas, as linhas onde são encontradas e as suas porcentagens são apresentadas a seguir, na ordem em que foram exibidas aos estudantes.

A imagem da Colina Nossa Senhora das Graças (a Santa), teve o elemento céu ocupando maior parte da Imagem (182 quadrículas), com $31,32 \%$, seguido do elemento construção (137 quadrículas), com 23,62\%.

O substituto da paisagem referente ao Parque Aquático de Irati, o componente com maior representatividade foi o céu (214 quadrículas), ocupando $36,9 \%$ da imagem, seguido do elemento árvore (136 quadrículas), com 23,45\% da figura e o elemento grama (129 quadrículas), preenchendo $22,24 \%$ da imagem. Os demais componentes, incluindo os culturais, tiveram menor representatividade.

A figura referente a cachoeira da localidade do Itapará, foram identificados cinco elementos constituintes da paisagem, componente vegetação (arbórea e arbustiva) foi o predominante (398 quadrículas) , 68,62\%, sendo identificado em 19 das 20 linhas da imagem, seguido do componente grama (73 quadrículas), com 12,58\%, evidenciando pertencer a um ambiente com elementos exclusivamente naturais.

A fotografia da cachoeira da localidade do Pinho de Baixo, também apresentou componentes exclusivamente naturais, sendo quatro classes identificadas, onde a vegetação foi o predominante (297 quadrículas), ocupando $51,21 \%$ da imagem, seguido do componente rocha (132 quadrículas), 22,76\% da figura.

\section{Análise dos dados do pré e pós-teste}

Os dados tabulados e submetidos ao teste de Wilcoxon são apresentados na Tabela 1 , obtidos entre os pré e pós-testes. Os primeiros resultados exibidos na tabela referem-se aos dados da etapa inicial do questionário, onde se pesquisou os conhecimentos específicos sobre a análise da paisagem, já a segunda parte, refere-se a etapa da análise a qual procurava-se saber qual era o conhecimento que os discentes possuíam a respeito dos pontos turísticos selecionados e os elementos que os compuseram. 
Tabela 1. Resultado do pré e o pós-teste pelo Wilcoxon

Table 1. Results of pre and post-test by Wilcoxon

\begin{tabular}{|c|c|c|c|c|}
\hline \multicolumn{5}{|c|}{ Primeira Parte } \\
\hline \multirow{2}{*}{ Questão } & \multicolumn{2}{|c|}{ Pio XII } & \multicolumn{2}{|c|}{ Luiza Rosa } \\
\hline & $p$ & $\boldsymbol{V}$ & $p$ & $\boldsymbol{V}$ \\
\hline 1 & $0,228176676^{\mathrm{ns}}$ & 47 & $0,752493649^{\text {ns }}$ & 12,5 \\
\hline 2 & $0,376971858^{\text {ns }}$ & 50,5 & $0,09467072^{\text {ns }}$ & 0 \\
\hline 3 & $0,008848774^{* *}$ & 0 & $0,533736835^{\text {ns }}$ & 14 \\
\hline 4 & 0,122215804 * & 9 & $0,571607645^{\mathrm{ns}}$ & 5 \\
\hline 5 & $0,625^{\text {ns }}$ & 3 & $0,75^{\mathrm{ns}}$ & 2 \\
\hline 6 & $0,066077965^{\mathrm{ns}}$ & 6,5 & $0,007841672^{* *}$ & 1 \\
\hline 7 & $0,5^{\mathrm{ns}}$ & 0 & $0,5^{\mathrm{ns}}$ & 0 \\
\hline 8 & $0,114490948^{\text {ns }}$ & 49 & $0,009090698^{* *}$ & 0 \\
\hline 9 & $0,398110674^{\mathrm{ns}}$ & 30 & $0,41330238^{\text {ns }}$ & 36 \\
\hline \multicolumn{5}{|c|}{ Segunda Parte } \\
\hline 1 & $0,5^{\mathrm{ns}}$ & 2,5 & $0,344704222^{\mathrm{ns}}$ & 2 \\
\hline 2 & $0,5^{\text {ns }}$ & 38,5 & $0,396438915 \mathrm{~ns}$ & 6 \\
\hline 3 & - & - & - & - \\
\hline 4 & $0,101127971^{\mathrm{ns}}$ & 11 & $0,097512538^{n s}$ & 0 \\
\hline 5 & $0,006339006^{* *}$ & 6 & $0,043825584^{*}$ & 5 \\
\hline 6 & $0,031753341^{*}$ & 6 & $0,104059235^{\text {ns }}$ & 1 \\
\hline 7 & $0,235885211^{\mathrm{ns}}$ & 6,5 & $0,181449208^{\text {ns }}$ & 0 \\
\hline 8 & $0,643649072^{\text {ns }}$ & 5,5 & $0,097512538^{n s}$ & 0 \\
\hline 9 & $0,25^{\mathrm{ns}}$ & 1 & $0,097512538^{\text {ns }}$ & 10 \\
\hline 10 & $0,551975159^{n s}$ & 10 & $0,105645429^{n s}$ & 1 \\
\hline 11 & $0,5^{\mathrm{ns}}$ & 1 & $0,5^{\mathrm{ns}}$ & 0 \\
\hline 12 & $0,461838018^{\text {ns }}$ & 6,5 & $0,207160449^{n s}$ & 4 \\
\hline 13 & $0,5^{\mathrm{ns}}$ & 0 & $0,097512538^{n s}$ & 10 \\
\hline 14 & $0,611452987^{n s}$ & 10,5 & $0,046875^{\star}$ & 2 \\
\hline 15 & $0,5^{\mathrm{ns}}$ & 0 & $0,5^{\mathrm{ns}}$ & 0 \\
\hline 16 & $0,719437544^{\mathrm{ns}}$ & 19 & $0,034287968^{*}$ & 1 \\
\hline 17 & $0,586213681^{\mathrm{ns}}$ & 1,5 & $0,5^{\mathrm{ns}}$ & 0 \\
\hline
\end{tabular}

** $=$ altamente significativo (se o nível
não-significativo (se o nível for $<0,05$ ).

Os resultados do teste Wilcoxon comprovaram que, com relação ao total das séries analisadas, a diferença entre o pré e pós-testes para $34,61 \%$ das perguntas realizadas foi altamente significativa ou significativa. Essa porcentagem invalida da hipótese nula $\left(\mathrm{H}_{0}\right)$, que supunha que não haveria diferença entre o pré e o pós-teste, evidenciando a importância da aula dada após o pré-teste.

A questão que se referia ao número de elementos identificados na foto 2 , a qual representava o parque aquático, foi a que apresentou diferença altamente significativa e significativa nas duas escolas onde foi aplicada a pesquisa. Essa disparidade refere-se provavelmente ao fato da compreensão de todos os elementos que compõe uma paisagem, realizado durante as aulas expositivas e interativas. 
A mesma realidade acontece para a questão número 3 e 4 da primeira parte da pesquisa, onde eram questionados quais elementos naturais e culturais compunham a paisagem.

A pergunta número 6 e 8 , as quais se referiam as forças naturais e como os seres humanos transformam a paisagem apresentaram-se altamente significativas em uma das escolas. As mesmas são complementares e provavelmente apresentaram esse resultado devido ao fato da apreensão dos conceitos ministrados durante as aulas expositivas, nas quais eram explicitados os conteúdos sobre os referidos assuntos e também a compreensão da diferenciação de ações realizadas pelos seres humanos e as que possuíam causas naturais.

A indagação a qual se referia aos elementos que eram possíveis identificar na foto 3 , da cachoeira do Pinho de Baixo, a mesma mostrou-se significativa na Escola Estadual Pio XII, fato que pode ser justificado provavelmente pelo fato da pesquisa que deveria ser realizada em casa com os familiares, pesquisando o nome do local, o que colaborou para a identificação de mais elementos que constituem o cenário apresentado.

O mesmo fato pode ser observado pelo o que aconteceu com o resultado das questões 14 e 16, onde era indagado o porquê da visita nas duas cachoeiras.

As demais questões $(65,39 \%)$ apresentaram diferenças não significativas.

A primeira parte do questionário, a qual se referia a conceitos e conhecimentos sobre análise e interpretação de paisagens, apresentou $77,78 \%$ das diferenças não significativas. A razão desse fato pode ser explicado devido os assuntos serem tratados na disciplina de geografia e ciências, no sexto ano. Na disciplina de geografia, a Diretriz Curricular apresenta o conteúdo básico como Formação e transformação das paisagens naturais e culturais, esperando-se que o aluno aproprie-se dos conceitos de região, território, paisagem, natureza, sociedade e lugar (PARANÁ, 2008b).

Na disciplina de Ciências, a orientação da Diretriz Curricular para o sexto ano, coloca o assunto referido dentro do conteúdo estruturante biodiversidade e conteúdo básico ecossistemas, esperando-se que o aluno compreenda a ocorrência de fenômenos meteorológicos e catástrofes naturais e sua relação com os seres vivos, assim como a relação com a paisagem com as modificações realizadas pelos seres humanos (PARANÁ, 2008a).

$\mathrm{Na}$ segunda parte do formulário entregue para a pesquisa, observou-se que $79,41 \%$ da diferença entre as questões mostraram-se como não significativas. Essa segunda seção de perguntas referia-se aos quatro pontos turísticos de Irati. A seguir é apresentado o gráfico com o resultado do questionamento da frequência de visitação dos locais (Figura 10). 


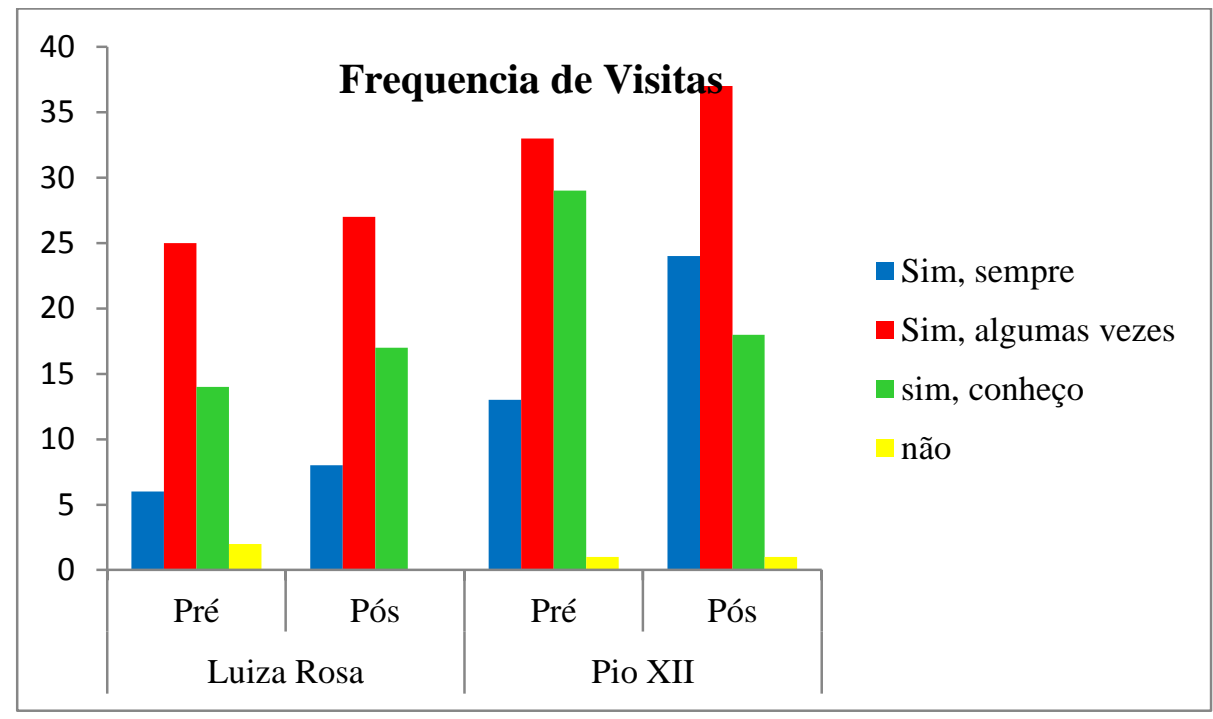

Figura 10. Frequência das visitas realizadas nos quatro pontos turísticos apresentado aos estudantes Figure 10. Frequency of visits in the four tourist spots shown to students

Essa porcentagem deve-se provavelmente pela grande frequência de visitas que os locais 1 e 2 apresentam, e a aspiração em conhecer os locais 3 e 4 . Mesmo residindo em bairros distantes, esses dois locais são bastante visitados, provavelmente por serem as poucas atrações para lazer na cidade. Essa situação pode ser comprovada através da Teoria do Reforço a qual conclui que as ações com consequências positivas sobre o indivíduo fazem as práticas serem repetidas no futuro. As consequências são positivas sempre que as pessoas sentem prazer com a sua própria performance (GIUSTA, 2013).

$\mathrm{Na}$ realização do teste de Qui-quadrado para a verificação se houve diferença de resultados entre as escolas, obteve-se como resultado o valor de $P=0,344$, com grau de liberdade um, onde se aceita a hipótese de igualdade estatística entre os números observados e esperados $\left(\mathrm{H}_{0}\right)$, portanto, os desvios não são significativos.

\section{CONCLUSÕES}

Com a realização desse trabalho pode-se concluir que a percepção dos discentes das duas escolas estaduais sobre a paisagem analisada foi muito influenciada por conhecimentos prévios e os conhecimentos adquiridos na disciplina de Geografia, os quais são trabalhados concomitantemente.

Em relação à paisagem utilizada para o estudo, consegue-se analisar que quanto maior é o número de visitações, como é o caso das duas paisagens que ficam na área urbana do município, confirma-se então o reforço da teoria, onde as ações as quais resultam em algo prazeroso ao indivíduo tendem a ser repetidas. 
Não houve diferenças entre as escolas, pois se tratam de duas escolas urbanas, onde se tem acesso fácil aos dois primeiros pontos turísticos e igual dificuldade para se conhecer os dois últimos locais exibidos.

Em vista disso, conclui-se que a escola é um bom espaço para o aluno apropriar-se de conteúdos sobre a paisagem e contextualizá-los dentro de uma visão ambiental, entrelaçando com a sua vivência, modificando assim a realidade presente e futura.

\section{REFERÊNCIAS}

ARAúJo, J. L. O.; ARAúJo, A. C.; ARAúJO, A. C. Percepção ambiental dos residentes do bairro Presidente Médici em Campina Grande, PB, no tocante à arborização local. Revista da Sociedade Brasileira de Arborização Urbana, Piracicaba, v.5, n.2, p. 67-81, 2010.

BIONDI, D.; FALKOWSKI, V. A. Avaliação de uma atividade de educação ambiental com o tema Solo. Revista Eletrônica do Mestrado em Educação Ambiental, Rio Grande, v. 22, p. 202-215, 2009.

BOBROWSKI, R.; VASHCHENKO, Y.; BIONDI, D. Qualidade visual da paisagem do Parque Natural Municipal Tanguá, Curitiba, Paraná. Revista da Sociedade Brasileira de Arborização Urbana, Piracicaba, v. 5, n. 2, p. 19-39, 2010.

CAMARGO, E. A. I.; FERRARI, R. A. P. Adolescentes: conhecimento sobre sexualidade antes e após a participação em oficinas de prevenção. Ciência e Saúde Coletiva, v. 14, n. 3, p. 937946, 2009.

CARRILLO, A. C.; BIONDI, D. A conservação do papagaio-da-cara-roxa (Amazona brasiliensis) no estado do Paraná - uma experiência de educação ambiental no ensino formal. Revista Árvore, Viçosa, v. 31, n. 1, p. 113-122, 2007.

COSTA, R. G. S.; COLESANTI, M. M. A contribuição da percepção ambiental nos estudos das áreas verdes. RA'E GA, Curitiba, v. 22, p. 238-251, 2011.

FANDI, A. C.; MELO, C. A interferência de um programa de educação ambiental no aprendizado de alunos das zonas rural e urbana. Revista educação, Santa Maria, v. 26, n. 2, p. $70-80,2001$.

FERNANDES, D. L.; MENEZES, V. O. Avaliação e hierarquização dos atrativos turísticos de Irati-PR. Revista Capital Científico, Guarapuava, v. 7, n. 1, p. 73-84, 2009.

FIGUEIREDO-FILHO, A.; DIAS, A. N.; STEPKA, T. F.; SAWCZUK, A. R. Crescimento, mortalidade, ingresso e distribuição diamétrica em Floresta Ombrófila Mista. Floresta, Curitiba, v. 40, n. 4, p. 763-776, 2010.

FREIRE, P. Extensão ou comunicação. Rio de Janeiro: Paz e Terra, 1979. 136p.

GEERDINK, S.; NEIMAN, Z. A educação ambiental pelo turismo. In.: NEIMAN, Z.;RABINOVICI, A. (orgs.) Turismo e meio ambiente no Brasil. Barueri, SP: Manole, 2010. p. 63-83. 
GIUSTA, A. S. Concepções de aprendizagem em práticas pedagógicas. Educação em Revista, Belo Horizonte, v. 29, n. 1, p. 17-36. 2013.

INSTITUTO BRASILEIRO DE GEOGRAFIA E ESTATÍSTICA (IBGE). Cidades - o Brasil município por município. Disponível em: < http://www.cidades.ibge.gov.br/xtras/perfil. php?lang=\&codmun=411070\&search=||infogr\%E1ficos:-informa\%E7\%F5es-completas $>$ Acesso em 16 set. 2016.

LACERDA, N. P.; SOUTO, P. C.; DIAS, R. S.; SOUTO, L. S.; SOUTO, J. S. Percepção dos residentes sobre a arborização da cidade de São José de Piranhas-PB. Revista da Sociedade Brasileira de Arborização Urbana, Piracicaba, v.5, n.4, p.81-95, 2010.

MARIN, A. A. Pesquisa em educação ambiental e percepção ambiental. Pesquisa em Educação Ambiental, Curitiba, v. 3, n. 1, p. 203-222, 2008.

MUCELIN, C. A.; BELLINI, M. Lixo e impactos ambientais perceptíveis no ecossistema urbano. Sociedade \& Natureza, Uberlândia, v. 20, n. 1, p. 111-124, 2008.

OLIVEIRA, L. de. Percepção Ambiental. Revista Geografia e Pesquisa, Ourinhos, v.6, n.2, p. 56-72, 2012.

OLIVEIRA, T. L. F.; VARGAS, I. A. Vivências integradas à natureza: por uma educação ambiental que estimule os sentidos. Revista eletrônica do mestrado em Educação Ambiental. Rio Grande, v. 22, p. 309-322, 2009.

PARANÁ, Lei $n^{\circ}$ 17.505, de 11 de Janeiro de 2013. Institui a Política Estadual de Educação Ambiental e o Sistema de Educação Ambiental e adota outras providências. Diário Oficial, Curitiba, PR. Disponível em:< http://www.legislacao.pr.gov.br/legislacao/listarAtosAno.do? action=exibir \&codAto=85172\&indice $=1$ \&totalRegistros=57\&anoSpan=2013\&anoSelecionado $=2$ 013\&mesSelecionado=0\&isPaginado=true $>$ Acesso em: 16 set. 2016.

PARANÁ. Secretaria de Estado da Educação. Diretrizes curriculares orientadoras para educação básica do estado do Paraná - Ciências, Curitiba, PR, 2008a. Disponível em:< http://www.educadores.diaadia.pr.gov.br/arquivos/File/diretrizes/dce_cien.pdf> Acesso em: 16 set. 2016.

PARANÁ. Secretaria de Estado da Educação. Diretrizes curriculares orientadoras para educação básica do estado do Paraná - Geografia. Curitiba, PR, 2008b. Disponível em:< http://www.educadores.diaadia.pr.gov.br/arquivos/File/diretrizes/dce_geo.pdf> Acesso em: 16 set. 2016.

SIDNEY, S. Estatística não-paramétrica para as ciências do comportamento. Rio de Janeiro: Mc Graw-Hill do Brasil, 1975. 448p.

SILVA, R. R. S.; BIONDI, D. Turismo e condições meteorológicas: o papel do clima sobre a demanda de visitação em um atrativo turístico de Curitiba, Brasil. Enciclopédia Biosfera, Goiânia, v. 10, n. 18, p. 3963-3963, 2014.

VENÂNCIO, D. L.; OLIVEIRA-FILHO, P. C.; DISPERATI, A. A. Uso do geoprocessamento em estudo ambiental na bacia hidrográfica do rio das Antas, Irati (Paraná). Ambiência, Guarapuava, v. 6, n. 1, p.135-146, 2010. 